\title{
Sementes como Fonte Alternativa de Substâncias Químicas com Atividade Alelopática ${ }^{1}$
}

\author{
Seeds as Alternative Source of Chemical Substances with Allelopathic Activity
}

SOUZA FILHO, A.P.S. ${ }^{2}$, TREZZI, M.M. ${ }^{3}$ e INOUE, M.H. ${ }^{4}$

\begin{abstract}
RESUMO - Na literatura mundial, observa-se predominância das folhas como meio preferencial de estudos de compostos químicos promissores, embora informações sobre outras frações da planta também sejam encontradas. Essa tendência se deve ao fato de que a maioria dos estudos mostra as folhas com atividade potencialmente alelopática de intensidade superior à das demais frações. Nesta revisão, procurou-se compilar e analisar as informações disponiveis sobre a importância das sementes como fonte alternativa de compostos químicos com atividade alelopática. São discutidas as variações na produção e na alocação de aleloquímicos em função do estádio ontogenético das sementes presentes no banco de sementes. É discutido também o papel dos aleloquímicos produzidos por sementes na repelência de insetos, na inibição do desenvolvimento de patógenos nas sementes, na inibição do desenvolvimento inicial de plantas daninhas e como sinalizador positivo para a simbiose com microrganismos do solo. Apresenta-se ainda a atividade alelopática de diversas substâncias isoladas de sementes, destacando-se os alcaloides, flavonoides, benzoxazinoides e resinas glicosídicas. Os estudos de aleloquímicos produzidos por sementes podem contribuir expressivamente para o melhor entendimento do papel ecológico que essas substâncias desempenham na ecologia química dos agro e ecossistemas.
\end{abstract}

Palavras-chave: aleloquímicos, função nas sementes, repelência de insetos, inibição de plantas daninhas, inibição de patógenos.

\begin{abstract}
In the literature, leaves predominate as preferred source of studies of promising allelopathic compounds, but information on other plant fractions are also found. This trend is due to the fact that most studies show that leaves have higher allelopathic potential than other plant fractions. In this review, we compiled and analyzed the information available on the importance of seeds as an alternative source of chemical compounds with allelopathic activity. We discussed the variations in production and allocation of allelochemicals at different ontogenetic stages of the seeds in the seed bank. The role played by the allelochemicals produced by the seeds on insect repellency, inhibition of the development of pathogens in seeds, initial development of competing plants and as positive signaling for the symbiosis with soil microbes were also studied. The allelopathic activity of several compounds isolated from the seeds was presented, especially alkaloids, flavonoids, resins, and benzoxazinoid glucosides. Studies of allelochemicals produced by the seeds can contribute significantly to a better understanding of the ecological role they play in the chemical ecology of agro-ecosystems and ecosystems.
\end{abstract}

Keywords: allelochemicals, role played in seeds, insect repellency, weed inhibition, pathogen inhibition.

1 Recebido para publicação em 14.10.2010 e aprovado em 10.2.2011.

2 Engōo-Agr ํo , Dr., Embrapa Amazônia Oriental, Trav. Dr. Enéas Pinheiro, S/N. 66095-100 Belém-PA, <e-mail:apedro@cpatu.embrapa.br>; ${ }^{3} \mathrm{Eng}^{\mathrm{o}}$-Agr ${ }^{\circ}$., Dr., Professor do Curso de Agronomia, Universidade Tecnológica Federal do Paraná, Campus de Pato Branco-PR; ${ }^{4}$ Engo $^{-}-$Agr $^{0}$., Dr., Universidade Estadual do Mato Grosso, Rod. MT358, Km 02, $78300-000$ Tangará da Serra-MT.

Planta Daninha, Viçosa-MG, v. 29, n. 3, p. 709-716, 2011 


\section{INTRODUÇÃO}

As plantas sintetizam grande quantidade de compostos diversificados quimicamente, que, uma vez liberados para o ambiente, desempenham papel preponderante na interação planta x planta, influenciando de maneira decisiva na dinâmica das espécies que compõem os agroecossistemas - fenômeno que Molisch, em 1937, denominou de alelopatia.

As principais rotas biossintéticas de produção desses metabólitos envolvem as vias do acetato, do ácido chiquímico e do mevalonato - sendo esta última via especificamente usada na sintese dos terpenoides (Einhellig, 1995). A distribuição dessas substâncias nas diferentes partes das plantas não é uniforme, tanto no aspecto qualitativo como quantitativo, no espaço e no tempo (Harbone, 1972). Diferentes estudos mostram que esses metabólitos podem ser encontrados em folhas, sementes, colmos, caules, cascas de troncos e de raízes, frutos, pólen, flores, rizomas, vagens e raízes de diferentes espécies de plantas (Putnam \& DeFrank, 1981; Friedmam \& Waller, 1983a; Smith \& Martin, 1994; Rodrigues et al., 2010). Entretanto, não há padrão fixo de distribuição dos aleloquímicos nas plantas, havendo variações em função de aspectos relacionados à idade de crescimento ou mesmo do estádio de desenvolvimento e das próprias necessidades da planta, que pode alocar, em determinado momento, por exemplo, seus aleloquímicos, prioritariamente, em maiores quantidades em determinada fração da planta. Estudo relacionado ao padrão de distribuição de aleloquímicos nas folhas e raízes do calopogônio (Calopogonium mucunoides), no intervalo de 2 a 12 semanas de crescimento, indicou atividade alelopática superior nas folhas no periodo de duas a seis semanas. A partir da oitava semana a atividade foi igual entre as duas frações, e na décima segunda semana as raízes apresentaram atividade alelopática inibitória mais elevada do que as folhas (Souza Filho et al., 2003).

Evidências indicam que a localização dos aleloquímicos nas plantas está relacionada a dois aspectos básicos: facilidade de liberação para o ambiente e função que podem desempenhar nas plantas, o que pode tornar seus efeitos mais imediatos e de maior magnitude.
Dessa forma, pode-se aventar que aquelas substâncias químicas envolvidas na defesa das plantas contra insetos raspadores, por exemplo, estariam localizadas preferencialmente nos tecidos mais externos da planta, enquanto aqueles compostos químicos envolvidos na interação entre plantas estariam localizados nos tecidos mais internos, sendo liberados apenas quando a sobrevivência das plantas estivesse ameaçada. Em alguns casos, substâncias produzidas em órgãos específicos são translocadas para diferentes órgãos das plantas, como é o caso da nicotina, alcaloide produzido exclusivamente pelas raízes das plantas, mas com função importante na proteção contra insetos fitófagos, como Manduca sexta. Neste caso, o ácido jasmônico regula rotas biossintéticas de produção de nicotina pelas plantas, aumentando notavelmente sua produção pelas raízes, de onde ela é distribuída para o restante da planta (Baldwin et al., 1997).

Um estudo pormenorizado da anatomia das sementes e da localização histológica de compostos fenólicos em duas espécies de Sesbania, conduzido por Ceballos et al. (1998), demonstrou que substâncias fenólicas estão localizadas principalmente no tegumento e no parênquima sub-hilar das sementes e que os tecidos atuam em conjunto para facilitar a exsudação de compostos durante o processo de embebição das sementes. O estudo também demonstra que a organização das estruturas das sementes permite a recuperação de substâncias defensivas e sua remobilização é benéfica para a sua sobrevivência. Marles et al. (2010) estudaram o acúmulo de polifenóis em feijão-preto em quatro ambientes e não observaram interação significativa para protocianidina (taninos condensados).

Outra questão importante a ser considerada é o estádio ontogenético das sementes presentes no banco de sementes do solo e seu potencial de liberação de substâncias alelopáticas. Sementes novas, dispersas há pouco tempo, são capazes de reabsorver açúcares, aminoácidos e outros metabólitos por transporte ativo - capacidade que é reduzida em sementes mais velhas, próximas da senescência. Assim, as sementes próximas à senescência apresentam maior capacidade de liberar metabólitos secundários e, portanto, o efeito alelopático aumenta com a sua idade, 
como foi comprovado pela liberação de cafeína de sementes de café (Friedman \& Waller, 1983b).

Especificamente em relação à avaliação da atividade alelopática de extratos brutos preparados a partir de sementes, muito se avançou nos últimos anos. Contudo, em relação a isolamento, identificação e testes de atividade alelopática de substâncias isoladas das sementes os avanços não foram os mesmos, havendo muito ainda a ser feito. Neste trabalho, procurou-se compilar e analisar as informações disponiveis sobre a importância das sementes como fonte alternativa de compostos químicos com atividade alelopática.

\section{Função dos aleloquímicos nas sementes}

Embora as sementes possam influenciar o equilíbrio químico no solo, a análise dos efeitos alelopáticos é extremamente complicada, devido à interação entre as várias substâncias alelopáticas existentes e pela sua dificuldade de extração, isolamento e purificação (Friedman \& Waller, 1983a).

Nesse sentido, poucas informações são encontradas na literatura abordando a função dos aleloquímicos nas sementes. Por exemplo, os mecanismos envolvidos nos processos que garantem a permanência das sementes no solo por longos periodos de tempo sem serem destruídas pelos organismos de decomposição não estão ainda bem entendidos. Entretanto, há consideráveis evidências mostrando que os aleloquímicos presentes nas cascas e outros tecidos da semente são impedimentos à ação microbiana; em alguns casos, essas substâncias ajudam a regular os mecanismos de germinação, o que, em tese, propicia a garantia das condições ambientais ideais para a formação de novas plântulas (Rice, 1984; Ceballos et al., 1998). Em termos da interação planta x planta, o papel ecológico dessas substâncias, muito provavelmente, está associado à liberação durante a germinação da semente, o que proporciona vantagem competitiva em relação às comunidades de plantas ao redor, reduzindo a agressividade das outras plantas ou reduzindo a proliferação de outras adversárias, o que garante o desenvolvimento e estabelecimento das plântulas.
A quantidade de aleloquímicos liberada pelas sementes é dependente da produtividade de sementes na área e do padrão de dispersão destas na superficie do solo. A taxa de liberação dos aleloquímicos das sementes para o solo dependerá de características ambientais que aceleram ou retardam o processo de envelhecimento das sementes. Além disso, sua disponibilidade para absorção por sementes ou plantas dependerá dos processos de interação dos aleloquímicos com o ambiente. Essas substâncias interagem no ambiente de forma semelhante à dos herbicidas e estão sujeitas aos processos de degradação por decomposição microbiana, fotólise e oxidação e a processos de remoção ou transferência, como adsorção e volatilização (Vidal \& Bauman, 1997).

Os compostos liberados pelas sementes estão também envolvidos na relação plantamicrorganismos, especialmente devido à formação de uma zona química, que afeta essa relação. Algumas substâncias pertencentes ao grupo das fitoalexinas - por exemplo, os isoflavonoides, produzidos pelas sementes - inibem o crescimento de muitos patógenos de plantas (Keen, 1975), enquanto outros flavonoides e betainas produzidas por sementes servem como sinal regulatório positivo para a simbiose com microrganismos do solo (Philips, 1992; Ceballos et al., 1998). Especificamente em relação à alfafa, luteolina foi a primeira molécula identificada nas sementes envolvida com a indução do gene regulador da fixação de nitrogênio (Peters et al., 1986). Em passado recente, Philips et al. (1995) verificaram relação entre os flavonoides e as betaínas na indução do gene da fixação do nitrogênio em sete espécies de Medicago. Outras funções específicas dos metabólitos liberados pelas sementes foram relatadas recentemente. Por exemplo, quercetina, um flavonoide dominante nas sementes de alfafa, afeta o crescimento de Rhizobium meliloti e promove a germinação de esporos e o crescimento hifal de micorrizas simbióticas (Gianinazzi-Pearson et al., 1989; Tsai \& Philips, 1991).

\section{Análise da atividade alelopática em sementes}

Quando se analisam as informações disponíveis na literatura, relacionadas à prospecção de atividade alelopática, observa-se, com certa 
preferência, o uso das folhas como fonte primária de identificação dessa atividade. É comum encontrar trabalhos envolvendo o uso de extratos aquosos, ou mesmo metanólicos ou ainda hidroalcoólicos preparados a partir de folhas, em testes e atividade alelopática. Bons exemplos desse tipo de abordagem são encontrados nos trabalhos de E1-Rokiek \& Eid (2009), Bertin et al. (2003), Anaya et al. (2003), Tseng et al. (2003) e Shiraishi et al. (2002), entre outros.

Muito dessa tendência se deve ao fato de que os testes envolvendo análises comparativas de diferentes frações das plantas (folhas, raízes, colmos, etc.) fornecem, em alguma medida, resultados mais intensos promovidos por extratos preparados a partir das folhas (Chon \& Kim, 2002; Tefera, 2002; Gatti et al., 2004; Rashid et al., 2010). Adicionalmente a essas informações, Tawaha \& Turk (2003) mostram que, para a espécie Brassica nigra, a intensidade dos efeitos alelopáticos varia na seguinte ordem decrescente de intensidade: folhas $>$ flores $>$ mistura da planta inteira $>$ colmos $>$ raízes, enquanto para Conyza albida a grandeza das inibições variou, de forma decrescente, na seguinte ordem: folhas>inflorescência>colmo (Economou et al., 2002).

No entanto, dependendo da espécie doadora, outras frações da planta podem conter maiores quantidades de aleloquímicos do que as folhas. Souza Filho (2002) estudou extratos hidroalcoólicos da parte aérea, sementes e raízes de feijão-de-porco (Canavalia ensiformis) e verificou que as sementes apresentaram atividade alelopática inibitória da germinação de sementes e do alongamento da radícula mais intensa do que a das demais frações, provavelmente pela presença de compostos fenólicos, como os ácidos clorogênico, ferúlico, p-anísico e genisteína (Mendonça, 2008).

Em estudo de mesma natureza, analisando os efeitos de extratos aquosos de folhas, raízes e sementes de leucena (Leucaena leucocephala) sobre a germinação e o desenvolvimento da radícula e do hipocótilo, Souza Filho et al. (1999) observaram maior intensidade dos efeitos para sementes, seguido de parte aérea e raízes. Os resultados foram atribuídos à mimosina, que se apresenta em maiores concentrações na semente em relação às outras frações da planta. Aparentemente, quando as sementes apresentam maior atividade alelopática em relação às demais frações da planta (folha, colmo, raízes e outras), muito provavelmente os resultados estão associados a um aminoácido não proteico, como é o caso da mimosina, nas leucenas. É importante salientar que, especialmente em sementes de leguminosas, pode ocorrer acúmulo impressionante de aminoácidos não proteicos, que pode chegar a $14 \%$ do peso das sementes, como é o caso do aminoácido 5-hidroxi-L-triptofano em Griffonia simplicifolia (Bell et al., 1976).

O conjunto dessas informações - mesmo reconhecendo-se as limitações das informações disponiveis em relação ao contingente total de trabalhos disponiveis - revela a importância das sementes como fonte de compostos alelopáticos, e o trabalho de Inoue et al. (2010) vem se juntar à relevância dessa abordagem.

Uma questão que tem merecido a atenção dos pesquisadores da área de alelopatia está relacionada ao fato de que os aleloquímicos presentes nas sementes, ao mesmo tempo em que produzem efeitos fitotóxicos sobre a germinação de sementes de outras espécies de plantas, não afetam a germinação da própria semente produtora (Fowden \& Lea, 1979). Quando se consideram os efeitos sobre o desenvolvimento do hipocótilo e da radícula, fitotoxicidade é observada tanto sobre outras plantas como sobre a própria planta, indicando a existência de efeitos autotóxicos. O fato de os agentes alelopáticos afetarem a germinação de outras sementes que não a própria semente é indicação da existência de algum mecanismo que protege as sementes dos efeitos de suas próprias toxinas. Fowden \& Lea (1979) descreveram alguns mecanismos pelos quais a planta evita os efeitos de seus próprios metabólitos, com especial ênfase nos aminoácidos não proteicos.

\section{Substâncias químicas com atividade alelopática em sementes}

Ao longo das últimas décadas, vários tipos de aleloquímicos foram isolados de um vasto número de espécies de plantas e, ao mesmo tempo, foram caracterizadas suas atividades 
biológicas (Rizvi \& Rizvi, 1992; Macias et al., 1999; Chaves et al., 2001). Muitos dos aleloquímicos conhecidos foram isolados e identificados a partir de folhas ou de plantas inteiras. Aleloquímicos isolados a partir de sementes são mais raros, porém estudos prévios têm demonstrado que lixiviados de sementes de muitas plantas podem alterar a germinação e o desenvolvimento de diferentes espécies de plantas (Suman et al., 2002).

A seguir, será analisada a atividade alelopática de diversas substâncias isoladas de sementes, reunindo-as por grupos de aleloquímicos.

\section{Alcaloides}

Os alcaloides constituem-se num vasto grupo de metabólitos com grande diversidade estrutural, representando cerca de $20 \%$ das substâncias naturais descritas (Henriques et al., 2001). Alcaloides vegetais têm se mostrado efetivos em seu papel medicinal e também exercem importante papel como substâncias de defesa contra insetos herbívoros (Guerra \& Nodari, 2001). Estudos demonstraram que sementes de Sesbania spp. contêm compostos tóxicos que são capazes de restringir o crescimento de outras espécies (Powell et al., 1990; van Staden \& Grobbelaar, 1995). Esse comportamento parece estar associado à presença da sesbanimida, um potente alcaloide presente nas sementes (van Staden \& Brobbellar, 1995).

A cafeina (1,3,7-trimetilxantina), extraída de sementes de café (Coffea arabica), apresenta seletividade diferencial entre espécies. O tratamento de sementes de caruru (Amaranthus spinosus) com 1,3,7-trimetilxantina resultou em redução da atividade da enzima amilase, responsável pela inibição da germinação dessa espécie, mas não afetou a atividade da amilase em sementes de Phaseolus mungo (Rizvi et al., 1987). A produção de cafeína é autotóxica para o café, pois é capaz, também, de bloquear a mitose de células em plântulas dessa espécie (Friedman \& Waller, 1983b).

\section{Flavonoides}

Os flavonoides representam um dos grupos fenólicos mais importantes e diversificados entre os produtos de origem vegetal. São conhecidos mais de 4.200 flavonoides, e o número de novas estruturas identificadas praticamente dobrou entre a década de 1980 e o final do século passado (Zuanazzi, 2001).

A partir das sementes de Sesbania virgata, Simões et al. (2008) isolaram e identificaram o flavonoide (+)-catequina, que é um aleloquímico rapidamente liberado para o ambiente, em altas concentrações ( $235 \mu \mathrm{g}$ por semente).

A atividade de aleloquímicos em sementes da espécie Abutilon theophrasti - uma dicotiledônea infestante com grande importância no hemisfério norte - foi investigada por Paszowski \& Kremer (1988). Eles isolaram seis compostos flavonoides (delfinidina, cianidina, quercetina, miricetina, catequina e epicatequina), capazes de inibir a germinação e o crescimento radicular de plantas-alvo e também de fungos decompositores de sementes, o que confere a essas substâncias importante papel no estabelecimento inicial das plântulas de Abutilon.

\section{Benzoxazinoides}

A concentração de aleloquímicos benzoxazinoides (ácidos hidroxâmicos, lactanas, benzoxazolinonas e derivados metilados do ácido hidroxâmico) entre tecidos de plantas de trigo foi avaliada por vários autores. Copaja et al. (1991) examinaram sementes germinadas de trigo e não encontraram benzoxazinoides, enquanto diversos autores encontraram concentrações variáveis de DIMBOA nas partes aéreas de plântulas de trigo (Niemeyer, 1988; Copaja et al., 1991; Nicol et al., 1992). A análise comparativa de benzoxazinoides em folhas, raizes e sementes, 10 dias após a semeadura de diferentes cultivares de trigo, em dois anos consecutivos, indicou que a quantidade desses compostos em sementes foi similar à das demais partes das plantas (Villagrasa et al., 2006). Os resultados indicam que as sementes contêm substâncias precursoras de benzoxazinoides e que essas substâncias são formadas tão logo as sementes são colocadas no solo. A maioria dos benzoxazinoides analisada teve a sua concentração reduzida com o avanço dos estádios ontogenéticos das plantas de trigo (Villagrasa et al., 2006).

Planta Daninha, Viçosa-MG, v. 29, n. 3, p. 709-716, 2011 


\section{Resinas glicosidicas}

Resinas glicosídicas são substâncias peculiares, pois são metabólitos anfipáticos, ou seja, sua estrutura contém porções lipofilicas (aminoácidos agliconas) e hidrofílicas (açúcares) (Pereda-Miranda \& Moustapha, 2003). Uma resina glicosídica, denominada triclorina, é extraída de Ipomoea tricolor, planta utilizada como cobertura vegetal no México, na América Central e na América do Sul, para suprimir o desenvolvimento de plantas daninhas (Anaya et al., 1990, 1995). Triclorina A é o principal composto fitotóxico presente em sementes de I. tricolor, com capacidade de inibir o desenvolvimento radicular de plântulas de tomate e caruru (Amaranthus spp.), com pouca atividade sobre capim-arroz (Echinochloa spp.). No entanto, esse composto possui atividade fungitóxica sobre Altenaria solani, e o efeito foi superior ao apresentado pelo fungicida Captan (Macias-Rubalcava et al., 2008). O modo de ação de triclorina A ocorre por meio do desacoplamento da fotofosforilação e inibição da sintese de ATP em cloroplastos de espinafre. Em altas concentrações (20 $\mu$ molar), também é um inibidor do FS II em nivel de plastoquinona $B\left(Q_{B}\right)$ (Achnine et al., 1999). Hipotetiza-se que a função ecológica de triclorina seja a defesa contra microrganismos fitopatogênicos e contra a competição com outras plantas daninhas.

\section{CONSIDERAÇÕES FINAIS}

Em qualquer balanço que se faça a respeito das informações disponíveis na literatura, que tratam da análise da atividade alelopática de extratos brutos, observa-se predominância das folhas como meio preferencial de estudos para indicação do potencial da planta estudada como fonte de compostos químicos promissores para o desenvolvimento de estudos mais avançados, embora informações sobre outras frações da planta, como raízes, colmos, flores, pólen e sementes, sejam também encontradas. Essa tendência se deve ao fato de que a maioria dos estudos mostra as folhas com atividade potencialmente alelopática de intensidade superior à das demais frações.

$\mathrm{O}$ número relativamente pequeno de trabalhos encontrados na literatura abordando as sementes como fontes de metabólitos com atividade biológica, alelopática ou mesmo outras de interesse do homem não deve, de forma alguma, ser visto como fator limitante imposto pelas sementes. Ao contrário, a literatura apresenta alguns bons exemplos de que as sementes podem contribuir expressivamente para melhor entendimento do papel ecológico que desempenham na ecologia química dos agro e ecossistemas.

Avanços no isolamento e identificação de metabólitos secundários produzidos por sementes trarão benefícios importantes em relação ao papel que essas substâncias têm como repelentes de insetos, como inibidoras do desenvolvimento de patógenos nas sementes e como inibidoras do desenvolvimento inicial de plantas daninhas. Adicionalmente, conhecimentos específicos poderão redundar em importantes avanços na elucidação dos processos de dormência, já que alguns dos metabólitos isolados de sementes, como as cumarinas, estão associados a esses processos.

Os resultados obtidos até hoje indicam que substâncias encontradas em sementes estão mais concentradas em tecidos específicos. Estudos mais aprofundados a esse respeito, realizados em nivel de espécie, serão úteis para maximizar o processo de extração de metabólitos em tecidos específicos e para estabelecer com maior clareza a relação entre a localização dos metabólitos e sua função nas plantas.

\section{LITERATURA CITADA}

ACHNINE, L. et al. Tricolorin A, a potent natural uncoupler and inhibitor of photosystem II acceptor side of spinach chloroplasts. Physiol. Plant., v. 106, n. 2, p. 246-252, 1999.

ANAYA, A. L. et al. Allelopathic potential of compounds isolated ftom Ipomoea tricolor Cav. (Convolvulaceae). J. Chem. Ecol., v. 16, n. 9, p. 2145-2152, 1990.

ANAYA, A. L. et al. Allelopathic potential of Ipomoea tricolor (Convolvulaceae) in a greenhouse experiment. J. Chem. Ecol., v. 21, n. 8, p. 1085-1102, 1995.

ANAYA, A.L. et al. Allelochemical potential of Callicarpa acuminate. J. Chem. Ecol., v. 29, n. 12, p. 2761-276, 2003.

BALDWIN, I. T. et al. Quantification, correlations, and manipulations of wound-induced changes in jasmonic acid and nicotine in Nicotiana sylvestris. Planta, v. 201, n. 4, p. 397-404, 1997. 
BELL, E. A.; FELLOWS, L. E.; QURESHI, Y. 5-Hydroxy-Ltryptophan: taxonomic character and chemical defence in Griffonia. Phytochemistry, v. 15, n. 4, p. 823-825, 1976.

BERTIN, C. et al. Laboratory assessment of the allelopathic effects of fine leaf fescues. J. Chem. Ecol., v. 29, n. 8, p. $1919-1928,2003$.

CEBALLOS, L. et al. Rapid deployment of allelochemicals in exudates of germinating seeds of Sesbania (Fabaceae): roles of seed anatomy and histolocalization of polyphenolic compounds in anti-pathogen defense of seedlings. Chemoecology, v. 8, n. 3, p. 141-151, 1998

CHAVES, M. H. et al. Separação e identificação de constituintes químicos polares dos galhos de Porcella macrocarpa. Química Nova, v. 190, n. 2, p. 307-309, 2001.

CHON, S. U.; KIM, J. D. Biological activity and quantification of suspected allelochemicals from alfafa plant parts. J. Agron. Crop Sci., v. 188, n. 4, p. 281-285, 2002

COPAJA, S. V.; NIEMEYER, H. M.; WRATTEN, S. D Hydroxamic acid levels in Chilean and British wheat seedlings. Ann. Appl. Biol. v. 118, n. 1, p. 223-227, 1991.

ECONOMOU, G. et al. Allelopathic effect of Conyza albida on Avena sativa and Spirodela polyrhiza. J.Agron. Crop Sci., v. 188, n. 3 , p. $248-253,2002$.

EL-ROKIEK, K. G.; EID, R. A. Allelopathic effects of Eucalyptus citriodora on amaryllis and associated grassy weed. Planta Daninha, v. 27, p. 887-889, 2009. (Edição Especial)

EINHELLIG, F. A. Mechanism of action of allelochemicals in allelopathy. In: DARKSHINI, K. M. M.; EINHELLIG, F. A. (Eds.). Allelopathy: organisms, process and applications. Washington: American Chemical Society. 1995. p. 97-116. (ACS. Symposium Series, 582).

FOWDEN, L.; LEA, P. J. Mechanism of plant avoidance of autotoxicity by secondary matabolites, especially by nonprotein amino acids. In: ROSENTHAL, G. A.; JANSEN, D. H. (Eds.). Herbivores: their interactions with secondary plant metabolites. New York: Academic Press, 1979. p. $135-160$.

FRIEDMAN, J.; WALLER, G. R. Seeds as allelopathic agents. J. Chem. Ecol., v. 9, n. 8, p. 1107-1117, 1983a.

FRIEDMAN, J.; WALLER, G. R. Caffeine hazards and their prevention in germinating seeds of coffee (Coffea arabica L.). J. Chem. Ecol., v. 9, n. 8, p. 1099-1106, 1983b.

GATTI, A. B.; PEREZ, S. C. J. G. A.; LIMA, M. I. S. Atividade alelopática de extratos aquosos de Aristolochia esperanzae $\mathrm{O}$. Kuntze na germinação e no crescimento de Lactuca sativa L. e Raphanus sativus L. Acta Bot. Bras., v. 18 , n. 3, p. 459-472, 2004
GIANINAZZI-PEARSON, P. V.; BRAZANTI, B.; GIANINAZZI, S. In vitro enhancement of spore germination and early hyphal growth of a vesicular arbuscular mycirrhizal fungus by host root exsudates and plant flavonoids. Simbioses, v. 7, n. 3, p. 243-255, 1989.

GUERRA, M. P.; NODARI, R. O. Biodiversidade: aspectos biológicos, geográficos, legais e éticos. In: SIMÕES et al. (Org.) Farmacognosia: da planta ao medicamento. Florianópolis: Universidade Federal de Santa Catarina, 2001. p. 13-26.

HARBONE, J. B. Phytochemical ecology. London: Academic Press, 1972. 272 p.

HENRIQUES, A. T.; KERBER, V. A.; MORENO, P. R. H. Alcalóides: generalidades e aspectos básicos. In: SIMÕES et al. (organiz.) Farmacognosia: da planta ao medicamento Florianópolis: Universidade Federal de Santa Catarina, 2001 p. 651-666.

INOUE, M. H. et al. Potencial alelopático de Annona crassiflora: efeitos sobre plantas daninhas. Planta Daninha, v. 28 , n. 3, p. $489-498,2010$

KEEN, N. T. The isolation of phytoalexins from germinating seed of Cicer arietinum, Vigna sinensis, Arachis hypogaea and other plants. Phytopathology, v. 65, n. 1, p. 91-92, 1975.

MACIAS, F. A. et al. Bioactive compounds from genus Helianthus. In: MACIAS, F. A. et al. (Eds.). Recent advances in allelopathy: a science for the future. Cadiz: International Allelopathy Society, 1999. p. 121-148.

MACÍAS-RUBALCAVA, M. L; HERNÁNDEZBAUTISTA, B. E.; ANAYA, A. L. Production of allelopathic glycosidic resins in seeds and early development stages of Ipomoea tricolor L. (Convolvulaceae). Allelopath. J., v. 21, n. 1, p. 107-118, 2008.

MARLES, M. A. S.; BALASUBRAMABIAN, P.; BEET, K. E. Differential accumulation of polyphenolics in black bean genotypes grow in four environments. J. Agric. Food Chem. v. 58, n. 4 , p. $7001-7006,2010$.

MENDONÇA, R. Determinação de aleloquímicos por HPLC/UV-Vis em extratos aquosos de sementes de Canavalia ensiformis e estudo da atividade alelopática. 2008. 82 f. Dissertação (Mestrado em Agronomia) Universidade de São Paulo, São Carlos, 2008.

NICOL, D. et al. A screen of worldwide wheat cultivars for hydroxamic acid levels and aphid antixenosis. Ann. Appl. Biol., v. 121, n. 1, p. 11-18, 1992

NIEMEYER, H. M. Hydroxamic acid content of Triticum species. Euphytica, v. 37, n. 3, p. 289-293, 1988.

PASZKOWSKI. W. J.; KREMER, R. J. Biological activity and tentative identification of flavonoid components in velvetleaf (Abutilon theophrasti Medik.) seed coats. J. Chem. Ecol., v. 14, n.7 , p. 1573-1582, 1988 
PEREDA-MIRANDA, R.; MOUSTAPHA, B. Biodynamic constituents in the mexican morning glories: purgative remedies transcending boundaries. Curr. Top. Med. Chem., v. 3, n. 2, p. 111-131, 2003

PETERS, N. K.; FROST, J. W.; LONG, S. R. A plant flavone, luteolin, induces expression of Rhizobium meliloti nodulation genes. Science, v. 233, n. 4767, p. 977-980, 1986.

PHILLIPS, D. A. et al. Release of flavonoids and betaines from seeds of seven Medicago species. Crop Sci., v. 35, n. 3, p. 805-808, 1995.

PHILLIPS, D. A. Flavonoids: plant signal tosoil microbes. Recent advances. Phytochemistry, v. 26, n. 2, p. 201-231, 1992.

POWELL, R. G.; PLANTINER, R. D.; SUFFENSS, M. Ocurrence of sesbanimide in seed of toxic Sesbania species. Weed Sci, v. 38, n. 2, p. 148-152, 1990.

PUTNAM, A. R.; DeFRANK, J. Use of allelopathy cover to inhibit weeds. In: CONGRESS PLANT PROT, 1981. Mineapolis. Proceedings... Mineapolis: 1981. p. 508-582.

RASHID, M. H.; ASAEDA, T.; UDDIN, M. N. The allelopathic potential of kudzu (Pueraria montana)

Weed Sci., v. 58, n. 1, p. 47-55, 2010.

RICE, E. L. Allelopathy. New York: Academic Press, 1984. $422 \mathrm{p}$.

RIZVI, S. J. H.; RIZVI, V. Exploration of allelochemicals in improving crop productivity. In: RIZVI, S. J. H.; RIZVI, V. (Eds.). Allelopathy. New York: Chapmam \& Hall, 1992. p. $443-472$.

RIZVI, S. J. H.; RIZVI, V.; MUKERJEE, D. 1,3,7Trimethilxantine an allelochemical from seeds of Coffea arabica: some aspects of its mode of action as a ntural herbicide. Plant Soil, v. 98, n. 1, p. 81-91, 1987.

RODRIGUES, I. M. C. et al. Prospecção química de compostos produzidos por Senna alata com atividade alelopática. Planta Daninha, v. 28, n. 1, p. 1-12, 2010.

SHIRAISHI, S. et al. Allelopathic activity of leaching from dry leaves and exudates from roots of ground cover plants assayed on agar. Weed Biol. Manag., v. 2, n. 3, p. 133-142, 2002.

SIMÕES, K. et al. Phitotoxic catechin leached of the tropical weed Sesbania virgata. J. Chem. Ecol., v. 34, n. 5, p. 681-687, 2008.

SMITH, A. E.; MARTIN, D. L. Allelopathic characteristics of three cool-season grass in the forage cosystems. Agron. J., v. 8, n. 2 , p. $243-246,1994$
SOUZA FILHO, A. P. S.; ALVES, S. M.; FIGUEIREDO, F. J. C. Efeitos alelopáticos do calopogônio em função de sua idade e da densidade de sementes da planta receptora.

Planta Daninha, v. 21, n. 2, p. 211-218, 2003.

SOUZA FILHO, A. P. S. Atividade potencialmente alelopática de extratos brutos e hidroalcóolico de feijão-deporco (Canavalia ensiformis). Planta Daninha, v. 20, n. 3, p. $357-364,2002$.

SOUZA FILHO, A. P. S. et al. Effects of aquoes extracts of leucaena on germination and radicle elongation of three forage grasses. In: MACIAS, F. A. et al. (Eds.). Recent advances in alllelopathy. Cadiz: Internation Allelopathy Society, 1999. p. $391-395$.

SUMAN, A. et al. Allelopathic influence of Vigna mungo (black gram) seeds on germination and radical growth of some crop plants. Plant Growth Reg., v. 38, n. 1, p. 69-74, 2002 .

TAWAHA, A. M.; TURK, M. A. Allelopathic effects of black mustard (Brassica nigra) on germination and growth of wild barley (Hordeum spontaneum). J. Agron. Crop Sci. v. 189, n. 1, p. 298-303, 2003

TEFERA, T. Allelopathic effects of Partenium hysterophorus extracts on seed germination and seedling growth of Eragrostis tef. J. Agron. Crop Sci., v. 188, n. 2, p. 306-310, 2002.

TSAI, S. M.; PHILLIPS, D. A. Flavonoids released naturally from alfafa promote development of symbiotic Glamus spores in vitro. Appl. Environ. Microbiol., v. 57, n. 5, p. $1485-1488,1991$.

TSENG, M. H. et al. Allelopathic potential of Macaranga tanarius L. J. Chem. Ecol., v. 29, n. 5, p. 1269-1286, 2003.

van STADEN, J.; GROBBELAAR, N. The effect of sesbanimide and Sesbania seed extracts on germination and seddling growth of a number of plant species. Environ. Exper. Bot., v. 35, n. 1, p. 321-329, 1995.

VIDAL, R. A.; BAUMAN, T. T. Fate of allelochemicals in soil. Ci. Rural, v. 27, n. 2, p. 351-357, 1997.

VILLAGRASA, M. et al. Benzoxazinoid allelochemicals in wheat: distribution among foliage, roots, and seeds. J. Agric. Food Chem., v. 54, n. 4, p. 1009-1015, 2006.

ZUANAZZI, J. A. S. Flavonóides. In: SIMÕES, C. M. O et al. (Org.) Farmacognosia: da planta ao medicamento. Florianópolis: Universidade Federal de Santa Catarina, 2001 p. $499-526$ 